\title{
PENGARUH ORIENTASI PASAR TERHADAP KINERJA PEMASARAN UMKM PRODUK OLAHAN IKAN DI KOTA JAMBI
}

\author{
Oleh: \\ Agesha Marsyaf \\ Dosen Tetap STIE Muhammadiyah Jambi \\ agesha.marsyaf.am $@$ gmail.com
}

\section{Ringkasan}

Tujuan dari penelitian ini adalah untuk menganalisis pengaruh orientasi pelanggan, orientasi pesaing dan orientasi koordinasi antar fungsi secara simultan dan parsial terhadap kinerja pemasaran UMKM Produk olahan ikan di Kota Jambi Penelitian ini menggunakan analisis regresi linear. Penelitian ini menggunakan sampel sebanyak 45 UMKM. Data dalam penelitian ini merupakan tabulasi dari tanggapan responden terhadap kuesioner tentang orientasi pasar dan kinerja UMKM. Hasil penelitian membuktikan bahwa secara simultan orientasi pasar (orientasi pelanggan, orientasi pesaing dan orientasi koordinasi antar fungsi) berpengaruh signifikan terhadap kinerja UMKM produk olahan ikan di Kota Jambi. Selanjutnya, uji secara parsial menemukan bahwa orientasi pelanggan dan orientasi pelanggan terbukti berpengaruh signifikan, sedangkan orientasi koordinasi antar fungsi tidak terbukti berpengaruh signifikan terhadap kinerja UMKM. Saran dari hasil penelitian bagi pelaku UMKM untuk lebih meningkatkan koordinasi antar fungsi dan perlu memberikan pendelegasian tugas pemasaran kepada staf karyawan.

Kata kunci: $\quad$ orientasi pasar, pelanggan, pesaing, koordinasi antar fungsi, kinerja UMKM.

\section{PENDAHULUAN}

Indonesia merupakan salah satu pendiri Persatuan Negara-Negara Asia Tenggara (Association of SouthEast Asia Nations - ASEAN). ASEAN dibentuk dengan maksud dan tujuan kepentingan negara-negara anggota dalam kerjasama antar bidang. Salah satu butir deklarasi ASEAN yang dimuat dalam www.asean.org adalah to accelerate the economic growth, social progress and cultural development in the region through joint endeavours in the spirit of equality and partnership in order to strengthen the foundation for a prosperous and peaceful community of South-East Asian Nations. (untuk mempercepat pertumbuhan ekonimi, kemajuan sosial dan pengembangan budaya dalam kawasan (ASEAN) melalui usaha-usaha bersama didalam semangat kesetaraan dan kebersamaan didalam memperkuat pondasi untuk kesejahteraan dan perdamaian negara-negara dikawasan Asia Tenggara).

Dengan semakin terintegrasinya perekonomian suatu Negara di era perdagangan bebas, maka keberadaan Usaha Mikro, Kecil dan Menengah (UMKM) di Indonesia juga dapat diharapkan menjadi salah satu pelaku usaha penting dalam mensejahterakan masyarakat. Untuk melaksanakan peranan tersebut, UKMM Indonesia harus memiliki daya saing globalnya. 
Menurut Tulus Tambunan (2013) liberalisasi perdagangan internasional yang meningkatkan persaingan internasional di pasar domestik akan berdampak buruk terhadap UMKM yang tidak efisien atau yang berdaya rendah, sementara itu akan menguntungkan UMKM yang efisien dan berdaya saing tinggi.

Provinsi Jambi dengan Luas perairan laut Jambi $+44.496 \mathrm{Km}^{2}$ dengan panjang pantai + $210 \mathrm{Km}$, memiliki potensi perikanan tangkap yang terkandung di dalamnya sekitar 71.820 ton/tahun, terdiri atas jenis-jenis ikan ekonomis penting seperti ikan patin, ikan Tenggiri, Bawal, Senangin, Kembung, Udang Ketak dan berbagai jenis udang lainnya, dan lain-lain (Sumber: Dinas Kelautan dan Perikanan Provinsi Jambi, 2014).

Berdasarkan ragam produk perikanan, menurut sumber Dinas Kelautan dan Perikanan Provinsi Jambi (30 April 2015), Provinsi Jambi memiliki 24 jenis ragam produk hasil perikanan yang diolah oleh pelaku Usaha Mikro, Kecil dan Menengah (UMKM).

Jumlah produksi terbesar untuk produk olahan yang berbahan baku bukan ikan patin adalah ikan asing sebanyak 1.007 .004 per tahun, terbesar kedua produk khas Jambi yakni Tekwan sebanyak 678.648 per tahun dan ketiga produk olahan Pempek sebanyak 457.788 per tahun. Sedangkan untuk produk olahan yang berbahan baku ikan patin yang terbesar adalah kerupuk ikan patin sebanyak 731.064 per tahun, posisi kedua Salai ikan sebanyak $46.356 \mathrm{~kg}$ per tahun dan ketiga abon ikan patin sebanyak 14.748 per tahun.

Permasalahan yang dihadapi oleh pelaku UMKM di Kota Jambi berdampak pada kinerja pemasaran yang tidak optimal. Permasalahan di atas diperkirakan karena faktor kurang mampu mengembangkan usahanya dengan mengacu pada usaha yang berorientasi pada pasar, peningkatan kualitas, produktivitas dan daya saing dengan memanfaatkan sumber daya yang ada dan selalu mengikuti perkembangan informasi dan teknologi. Menurut Narver dan Slater (1990) kemampuan perusahaan untuk memahami keinginan dan kebutuhan konsumen dan menyediakan produk atau jasa yang diinginkan dan dibutuhan konsumen dikenal dengan istilah orientasi pada pasar atau market orientation.

Berdasarkan uraian latar belakang penelitian, maka dapat disimpulkan yang menjadi pertanyaan penelitian ini adalah "Bagaimanakah Orientasi Pelanggan, Orientasi Pesaing dan Orientasi koordinasi antar fungsi Berpengaruh terhadap kinerja Pemasaran UMKM Produk olahan ikan di Provinsi Jambi” 


\section{METODOLOGI PENELITIAN}

Desain penelitian yang digunakan dalam penelitian ini adalah desain penelitian deskriptif kuantitatif untuk menjelaskan analisa, permasalahan, melakukan pemahaman dasar pada teori dari penelitian terdahulu dan kemudian mengungkapkan hipotesis yang akan diuji. jenis data yang digunakan dalam penelitian ini adalah Data primer yang akan disajikanberasal dari data yang diperoleh dengan survey lapangan melalui kuesioner yaitu data tentang tingkat tanggapan responden atas orientasi pasar, yaitu orientasi pelanggan, orientasi pesaing, dan koordinasi antar fungsi serta kinerja UMKM, Data sekunder yang diperoleh adalah jenis data yang bukan diperoleh sendiri pengumpulannya dalam penelitian. Data sekunder diperoleh melalui literatur-literatur, jurnal penelitian terdahulu dan bacaan-bacaan lain yang berhubungan dengan penelitian ini.

Data sekunder diperoleh melalui studi pustaka, mempelajari literatur dan jurnal, pencarian melalui media internet guna memperoleh buku-buku untuk mendapatkan konsep-konsep dan defenisi-defenisi yang berhubungan dengan penelitian ini.

Populasi dalam penelitian ini pelaku usaha (UMKM) produk olahan ikan di kota Jambi tercatat sebanyak 83 UMKM dan 825 jenis produk olahan ikan pada tahun 2014 (sumber renstra diskop UMKM Kota Jambi.

Jumlah sampel pada penelitian ini dihitung berdasarkan rumus slovin sebagai berikut:

Jumlah UMKM produk olahan ikandi kota Jambi $=83$

$$
\begin{aligned}
& n=\frac{\mathbf{N}}{\mathbf{1}+\mathbf{N ~}^{2}} \\
& n=45 \text { orang }
\end{aligned}
$$

Keterangan:

$\mathrm{n} \quad$ = jumlah sampel

$\mathrm{N}=$ jumlah populasi

$\mathbf{e}^{2}=$ ketidakpastian yang dapat ditoleransi $(10 \%)$

Teknik penarikan sampel adalah suatu cara mengambil sampel yang representatif dari populasi. Metode non probability sampling digunakan untuk pengambilan sampel karena tidak diketahui seberapa besar populasi dan setiap elemen dari populasi tidak memiliki kesempatan yang sama untuk menjadi sampel. Jenis non probability sampling yang digunakan adalah purposive sampling dimana peneliti memilih sampel secar subyektif. Pemilihan sampel ini dilakukan karena informasi yang dibutuhkan bisa didapatkan dari satu kelompok sasaran tertentu yang mampu memberikan informasi dan memenuhi kriteria yang dibutuhkan (Sugiyono, 2012). 
Variabel yang mempengaruhi variabel lain atau yang diselidiki hubungannya dan pengaruhnya. Penelitian ini menggunakan variabel bebas adalah orientasi pasar $(\mathrm{X})$ Orientasi Pelanggan $\left(\mathrm{X}_{1}\right)$ Orientasi Pada Pesaing $\left(\mathrm{X}_{2}\right)$ Koordinasi Antar Fungsi $\left(\mathrm{X}_{3}\right)$.Variabel terikat adalah variabel yang nilainya dipengaruhi oleh variabel bebas. Tujuan dari metode dependent ini adalah untuk menentukan apakah variabel bebas mempengaruhi variabel terikat secara individual dan atau bersamaan. Dalam penelitian ini yang menjadi variabel terikat adalah Kinerja pemasaran UMKM.

Uji statistik F pada dasarnya menggambarkan kelayakan suatu model. Model yang baik memiliki variabel-variabel yang mampu menjelaskan permasalahan dalam penelitian. Untuk menguji signifikansi hipotesis secara bersama-sama, digunakan uji F.

Mencari F-hitung dengan rumus

$$
\mathrm{F}=\frac{R^{2} /(n-k)}{\left(1-R^{2}\right) /(k-1)} \text { Untuk menguji signifikan tidaknya variabel orientasi pelanggan, }
$$

orientasi pesaing, koordinasi antar fungsi terhadap kinerja pemasaran UMKM, maka digunakan uji $\mathrm{t}$ ( $\mathrm{t}$ test) dengan rumus :

$$
\mathrm{T} \text { (hitung) }=\frac{\operatorname{Se} \beta_{\mathrm{i}}-\beta_{\mathrm{i}}}{\operatorname{Se}\left(\beta_{\mathrm{i}}\right)}
$$

Dimana :

$\beta_{\mathrm{i}} \quad=$ Koefisien regresi hasil estimasi

$\operatorname{Se}\left(\beta_{\mathrm{i}}\right)=$ Simpangan baku

Adapun model persamaan regresi yang dapat diperoleh dalam analisis ini adalah sebagai berikut :

sebagai berikut:

$Y=\boldsymbol{\alpha}+b_{1} X_{1}+b_{2} X_{2}+b_{3} X_{3}+e$

Keterangan:

$Y=$ Variabel terikat (kinerja pemasaran)

$\alpha=$ Bilangan konstan

$b_{1} b_{3}=$ Koefisien regresi untung mrngukur perubahan $X$ dan $Y$

$X_{1}=$ Orientasi pelanggan

$X_{2}=$ Orientasi pesaing

$X_{3}=$ Koordinasi antar fungsi 
$e=$ Standar eror

\section{HASIL PENELITIAN}

Tabel . Hasil Uji Simultan $\left(\right.$ ANOVA $\left.^{\mathrm{b}}\right)$

\begin{tabular}{|c|c|c|c|c|c|c|}
\hline \multicolumn{2}{|c|}{ Model } & $\begin{array}{l}\text { Sum of } \\
\text { Squares }\end{array}$ & df & Mean Square & $\mathrm{F}$ & Sig. \\
\hline \multirow[t]{3}{*}{1} & Regression & 79.236 & 3 & 26.412 & 23.767 & $.000^{\mathrm{b}}$ \\
\hline & Residual & 45.564 & 41 & 1.111 & & \\
\hline & Total & 124.800 & 44 & & & \\
\hline
\end{tabular}

a. Dependent Variable: Kinerja_UMKM

b. Predictors: (Constant), Koordinasi_Antar_Fungsi, Orientasi_Pesaing, Orientasi_Pelanggan

Dari hasil perhitungan uji $\mathrm{F}$ pada tabel di atas pada bagian ANNOVA diperoleh nilai Pvalue sebesar 18,048 dengan tingkat signifikansi $0,000^{a}$. Sementara itu, nilai P-value yang diperoleh ketika menggunakan alpha 0,05 dan derajat bebas pembilang $(\mathrm{k})$ sebesar 3 dan derajat bebas penyebut sebesar 41 adalah sebesar 1,312. Sesuai dengan ketentuan sebelumnya bahwa jika nilai P-value kecil dari nilai alpha dari nilai F-tabel maka dapat diambil keputusan bahwa hipotesis nol $\left(\mathrm{H}_{0}\right)$ ditolak dan menerima $\mathrm{H}_{1}$. Menerima $\mathrm{H}_{1}$ berarti menerima ketentuan yang menyatakan bahwa terdapat pengaruh yang signifikan antara orientasi pelangan, orientasi pesaing, dan koordinasi antar fungsi terhadap kinerja UMKM produk olahan ikan di kota Jambi, serta menolak $\mathrm{H}_{0}$ yang menyatakan bahwa tidak terdapat pengaruh yang signifikan antara orientasi pelanggan, orientasi pesaing, koordinasi antar fungsi terhadap kinerja UMKM olahan ikan di kota Jambi.

\section{Uji Signifikansi secara Parsial (Uji t)}

Tabel 5.24. Hasil Uji Parsial

\begin{tabular}{|c|c|c|c|c|c|c|}
\hline \multirow{2}{*}{\multicolumn{2}{|c|}{ Model }} & \multicolumn{2}{|c|}{$\begin{array}{c}\text { Unstandardized } \\
\text { Coefficients }\end{array}$} & \multirow{2}{*}{$\begin{array}{c}\text { Standardized } \\
\text { Coefficients } \\
\text { Beta }\end{array}$} & \multirow[b]{2}{*}{$t$} & \multirow[b]{2}{*}{ Sig. } \\
\hline & & $\mathrm{B}$ & Std. Error & & & \\
\hline & (Constant) & 1.705 & 1.851 & & .921 & .362 \\
\hline & Orientasi pelanggan & .369 & .157 & .331 & 2.343 & .024 \\
\hline & Orientasi pesaing & .420 & .139 & .419 & 3.031 & .004 \\
\hline & $\begin{array}{l}\text { Koordinasi antar } \\
\text { fungsi }\end{array}$ & .165 & .155 & .142 & 1.063 & .294 \\
\hline
\end{tabular}

Sumber : Hasil pengolahan data spss versi 23.0 
Selanjutnya, pada variabel orientasi pesaing mendapatkan t-hitung sebesar 3,031 dan angka signifikansi sebesar 0,004 lebih kecil dari level of significancy 0,05 artinya orientasi pesaing berpengaruh secara signifikan terhadap kinerja UMKM. Sementara itu, untuk variabel Koordinasi Antar Fungsi mendapatkan angka t-hitung sebesar 1,063 lebih kecil dari angka ttabel dan angka signifikansi sebesar 0,294 yang lebih besar dari angka level of significancy 0,05 , dapat disimpulkan bahwa variabel koordinasi antar fungsi tidak memiliki pengaruh yang signifikan terhadap kinerja UMKM di kota Jambi.

\section{Koefisien Determinasi $\left(\mathbf{R}^{\mathbf{2}}\right)$}

Hasil perhitungan outpus SPSS sebagaimana yang terlihat pada tabel di atas merupakan bagian model summary yang menunjukkan besaran koefisien korelasi berganda dengan nilai koefisien determinasi atau Rsquare sebesar 0,635.

\section{Model Summary ${ }^{\mathrm{b}}$}

\begin{tabular}{|l|c|r|r|r|r|}
\hline Model & $\mathrm{R}$ & R Square & $\begin{array}{c}\text { Adjusted R } \\
\text { Square }\end{array}$ & $\begin{array}{c}\text { Std. Error of } \\
\text { the Estimate }\end{array}$ & $\begin{array}{c}\text { Durbin- } \\
\text { Watson }\end{array}$ \\
\hline 1 & $.797^{\mathrm{a}}$ & .635 & .608 & 1.054 & 1.494 \\
\hline
\end{tabular}

a. Predictors: (Constant), Koordinasi_Antar_Fungsi, Orientasi_Pesaing, Orientasi_Pelanggan

b. Dependent Variable: Kinerja_UMKM

Nilai koefisien determinasi sebesar 0,635 menyatakan bahwa 63,5\% variasi kinerja UMKM dijelaskan oleh variabel orientasi pelanggan, orientasi pesaing dan koordinasi antar fungsi. Sedangkan sisanya sebesar 36,5\% dijelaskan oleh sebab-sebab lain diluar model penelitian.

\section{Kesimpulan}

Berdasarkan hasil analisis dan pembahasan yang telah diuraikan sebelumnya, maka dapat ditarik beberapa kesimpulan dari keseluruhan hasil penelitian sebagai berikut :

1. Variabel orientasi pelanggan berpengaruh positif dan signifikan terhadap kinerja UMKM.

2. Variabel orientasi pesaing berpengaruh positif dan signifikan terhadap kinerja UMKM

3. Variabel koordinasi antar fungsi berpengaruh positif dan tidak signifikan terhadap kinerja UMKM.

\section{DAFTAR PUSTAKA}

Ade Oktavia. (2009). “Orientasi Pasar Dan Kualitas Layanan Jasa Rumah Sakit Milik Pemerintah Di Kota Jambi. “Jurnal Penelitian Universitas Jambi Seri Humaniora Vol 11(1). 
Ade Oktavia. (2013). “ Faktor- faktor pendorong terbentuknya orientasi pasar ekspor batik jambi . “Jurnal Dinamika Manajemen Vol 2(3).

Adinoto.,(2013), Pengaruh Orientasi Pasar dan Perilaku Kewirausahaan Terhadap Kepekaan Perusahaan Dan Implikasinya Pada Kinerja Perusahaan: Studi pada Penyalur Sepeda Motor di Indonesia, Ultima Management, Vol 4, No. 10.

Alam, M.M., (2013), Effect of Market Orientation on Small Business Perormance in Small Town In Malaysia: An Emprical Study on Malaysian Small Firms, Journal of Strategic Marketing, Vol 1, No. 3.

Bhuian, S.N., Menguc, B., \& Bell, S.J. (2005). Just entrepreneurial enough: The moderating effect of entrepreneurship on the relationship between market orientation and performance. Journal of Business Research, 58: 9-17.

Chen, M., \& Hambrick, D. C. (1995). Speed, stealth and selective attack: How small firms differ from large firms in competitive behavior. Academy of Management Journal, 38(2): 453-482.

Deshpande, R., \& Farley, J. (1999). Corporate culture, custome orientation,and innovativeness in Japanese firms. Journal of International Marketing, 57 (1): 23-38.

Forbes, D.P. (2005). Managerial determinants of decision speed in new ventures. Stategic Management Journal, 26 (9): 355-366.

Hult, G. T., Ketchen, Jr., David J., \& Slater, S.F. (2005). Market Orientation and Performance: An Integration Of Disparate Approaches. Strategic Management Journal, 26 (12): 1173-1181.

Jaworski, B.J., \& Kohli, A.K. (1993). Market Orientation: Antecedents and consequences. Journal of Marketing, 52 (7): 53-70.

Jaworski, B.J., \& Kohli, A. (1996). Market Orientation: Review, refinement, and roadmap. Journal of Market Focused Management, 1 (2): 119-35.

Kotler, P. dan Keller, K. (2000), Marketing Management, Millennium Edition, 12c, Prentice Hall, Inc.

Kotler, P. (2000). Marketing Management. NJ; Prentice Hall.

Kara, A., Spillan, J. E., \& Deshields, O. W. (2005). The Effect of a Market Orientation on Business Performance: A Study of Small-Sized Service Retailers Using Markor Scale. Journal of Small Business Management,43(2): 105-118.

Lie, Y., Zhao, Y., Tan., J., \& Liu, Y. (2008). Moderating effects of entrepreneurial orientation on market orientation-performance linkage: Evidence from Chinese Small Firms. Journal of Small Business Management, 46 (1): 113-133. 
Narver, J. and Slater, S. (1990). The effect of a market orientation on business profitability. Journal of Marketing, 54 (10): 20-35.

Noble, C.H., Sinha, R.K., \& Kumar, A. (2002). Market orientation and alternative strategic orientations: A longitudinal assessment of performance implications. Journal of Marketing, 66 (4): 25-39.

Perengki, Susanto. “Pengaruh orientasi pasar pada kinerja perusahaan kecil .” Jurnal Kajian Manajemen Bisnis 1 ( 2012).

Slater, S. F., \& Narver, J. C. (1994). Does competitive environment moderate the market orientation-performance relationship?, Journal of Marketing, 58(1): 46-55.

Slater, S. F., \& Narver, J.C. (1995). Market orientation and the learning organization. Journal of Marketing, 59 (7): 63-74.

Slater SF, \& Narver JC. (1998). Customer-led and market-oriented: let's not confuse the two. Strategic Management Journal, 19(10): 1001-1006. 